\title{
A Study on the Planning of New Campus under the Concept of Green Ecology
}

\author{
Li Hongjun \\ College of Road and Rail, Hubei Communications Technical College, Wuhan, China Zip Code: 430079
}

\begin{abstract}
Under the background of the era with the theme of green development, higher requirements have been put forward for the planning of new campus in colleges and universities. Campus planning under the concept of green emphasizes the ecological green campus model, creates a beautiful and elegant campus environment with outstanding green ecological characteristics, and realizes the green development and sustainable development of new campus in colleges and universities. The campus planning should fully consider the natural landscape, coordinate with the surrounding environment, combine the regional and cultural characteristics, integrate the unique human environment characteristics of traditional campus, and form a unique human campus atmosphere. Based on the terrain and the water body, the planning is supposed to inherit the elements of good campus space and create a unique campus space personality.
\end{abstract}

\section{Introduction}

With the strong support of the state for vocational education, Hubei Province vigorously develops its economy and accelerates the adjustment of its economic structure. At the same time, it deepens the reform in the field of education, expands the enrollment scale of schools, and responds to a series of problems brought about by the expansion of enrollment scale in the form of reconstruction and expansion.

At present, Hubei Communications Vocational and Technical College has three campuses, namely, the main campus in Hongshan, MaChangHu campus in Hanyang and Mulan campus in Huangpi. The campuses are scattered in three towns of Wuhan, which are far away from each other, resulting in the state that schools need to pay more resources to coordinate in management, with high operating costs. And it is difficult for all campuses to share educational resources.

Thus, the construction of new campus came into being. The distance between the campuses is too far, the space of the school buildings is seriously insufficient, the student numbers that the teaching buildings can accommodate are limited, and the function division is unreasonable. All these factors will limit the development of Hubei Traffic Vocational and Technical College. The fact proves that the construction of the new campus of Hubei Traffic Vocational and Technical College is an inevitable trend to solve the above problems.

\section{Necessity of Green Campus Construction on New Campus}

The construction of the new campus of Hubei Communications Vocational and Technical College should be scientifically planned according to the overall idea of "resource-saving and environment-friendly" ecological campus. It is required to improve the teaching quality, optimize the learning and accommodation environment of students, beautify the campus environment, in order to train more excellent talents for the transportation system, promote the development of the transportation system, and meet the requirements of the digital ecological campus with 13000 full-time students and 800 teaching staff. After the completion of the project, the school running conditions will be further improved, the teaching environment will be optimized, the teaching quality is going to be developed, more excellent talents will be trained for the transportation industry, and the development of the transportation industry is certain to be promoted. Therefore, it is very urgent and necessary to guide the practice of new campus construction with the idea of sustainable development under the background of green concept.

Developing green campus, actively promoting the application of passive and low-cost technologies, and accounting the benefits and costs from the whole life cycle of green campus can meet the market development needs and local economic conditions, and finally reduce the flashiness [1]. At the same time, through the construction of the green campus, the campus will be built into a better teaching base for sustainable education of all majors. And the positive role of the green campus

\footnotetext{
* Corresponding author: Leehj2004@163.com
} 
for the environmental education and concept promotion of the students will be emphasized, the indoor and outdoor environment of the campus is going to be improved, and a healthy and pleasant working and living environment will be provided for all the teachers and students, reflecting the unity of social, environmental and economic benefits[2]. Through the construction of green campus, students can promote the energy-saving technology and concept to the whole society, which can play a huge radiation role and social benefits.

\section{Principles and Overall Framework of Green Planning and Design for New Campus Construction}

\subsection{Principles of Green Planning and Design for New campus Construction}

The new campus planning idea of Hubei Transportation Vocational College reflects: brand characteristic, teaching humanism, information intelligence, landscape feature. The design concept covers three aspects: first, context inheritance (torch, Golden Dragon and breeding in the way of implication) shows the foundation of the school's education; second, landscape context (through the use of terrain) creates the linear valley landscape and campus functional zoning, and strengthens the idea of "forest valley, landscape campus". The third is to emphasize the "experience" and "communication" through the careful design of four different levels of places: landscape, scene, street view and circumstance, and strive to create a personalized campus environment with "communication and experience" as the core.

\subsection{New campus planning reflecting cultural heritage}

Education is the main form of cultural heritage. "Emphasizing Morality", "Inspiring", "Devoting to Learning" and "Admiring the Capable" are the foundation of the academic heritage of Hubei Transportation Technology Vocational College. This scheme is based on the understanding of the meaning and the integration of the meanings. Through the similar design techniques, the grand blueprint of "cultivating people for a hundred years" is written by means of "Torch", "Golden Dragon" and "Breeding".

The construction of the overall campus environment pays attention to the integration of the surrounding natural environment, especially the infiltration of the west side's ecological landscape of Tangxun Lake, combing the current situation, using the ups and downs of the terrain to form a valley landscape in the center of the campus, so as to create a personalized garden campus landscape. The art space set up in the center of campus landscape lake is the highlight of the school. "Forest valley, landscape campus" describes the dialogue between culture and nature in the context of experience and communication.

\subsection{Clear Functional Division of New Campus}

The campus function partition is clear, the arrangement is reasonable, the connection is convenient. Different sections will not be interfered with each other, the teaching and life request is to be satisfied, and certain development space is given. The base keeps good traffic and transportation contact with the outside. The entrances and exits as well as the internal roads meet the distribution requirements of the flow of people and vehicles. The flow lines of each movement are smooth and short. The campus building layout fully considers the local natural landscape, coordinates with the surrounding environment, combines the regional features and cultural characteristics, and forms the unique campus style of Hubei Transportation Vocational and Technical College. It integrates the different cultural environment characteristics of the traditional campus and forms a unique cultural campus atmosphere[3]. Based on the terrain and coherent water, it inherits the elements of good campus space, and manages to create a unique campus space personality[4].

The plan forms a planning structure of "one center, one belt, four axes, six areas and multipoint". "One center" is planned to form the main center of the campus by combining the artistic space with the landscape lake excavated in the center of the base, together with the wooden plank road and the valley. "one belt" combines the current terrain, through the introduction of Tangxun Lake water system to the lowest part of the center of the campus, and makes use of the current site elevation difference to create an arc-shaped landscape valley belt (Forest Valley), running through the north and south of the campus. "Four axes", the concept refers to the eastwest functional main axis and the other three functional sub axes. The former connects the main entrance on the west side of the campus, the graphic information center and the track and field training ground, the latter combines the north entrance of the campus and the art space, the east entrance of the campus and the art space, and the north-south traffic in the middle of the teaching area.

"Six areas" combine the school's functional facilities to form landscape area, teaching area, student living area, teacher living area, sports area and sharing area.

The landscape area plans to introduce the water system of Tangxun Lake into the base, excavate the landscape lake in the center of the base according to the topography of the base, and build an arc-shaped valley landscape throughout the north and south of the whole campus.

Teaching area is located on the west side of the campus, which is composed of teaching building complex of each department, traffic engineering test and detection center, public teaching building group, graphic information center, academic exchange and training center.

Student living area is located in the north of the campus, mainly composed of student dormitories, student canteens, supporting facilities, training practice bases, $5 \mathrm{~m}$ diving platform, swimming pool, pool viewing and sports facilities. 
Teachers' living area is planned to be located in the south of the campus, which is relatively independent. It is connected with the north of the campus through the underpass road, mainly composed of public rental housing for the teaching staff.

The sports area is arranged along the expressway around the city in the southeast of the school base, mainly composed of mountain path field and ball games field.

Sharing area is located in the departments of the campus, including the school health center, administrative building, student comprehensive service center, etc.

"Multipoint": combines with the main entrance of the campus, the image and text information center, the fourway training ground, the East Gate Population Square, the academic exchange and training center and the central green space of the teachers' living area, which serve as multiple function nodes.

\subsection{The Design of the New Campus Landscape System}

It is planned to form a "one center, one belt, four axis and multipoint" landscape system.

"One center": The landscape core is formed around the art space of the campus landscape area.

"One belt": The core landscape belt runs through the north and south of the campus.

"Four axes": The landscape principal axis is formed around the main entrance of the campus, the graphic information center, and the track and field training field; the other three secondary axes are formed around the East Population Art Space, the north entrance art space, and the Qihang Avenue.

"Multipoint": They are a number of landscape nodes, which are formed around the image and text information center, academic exchange and training center, etc.

The campus planning emphasizes the ecological green campus mode and forms a unique and elegant campus environment[5]. The green space system is mainly composed of mountains, water bodies, public green spaces, including sports green space, group green space and building attached green space, and the green coverage rate of the occupied land is up to $60 \%$.

In combination with the climate characteristics of Hubei, the square space paved with pure hard ground shall be arranged as less as possible in the planning, and the public space of grassland, green square and water surface shall be adopted more, and shade trees shall be planted to create comfortable outdoor activity spaces. Through the organization of the main landscape on the axis, the landscape sequence and climax are formed. For example, the open green land to the east-west direction is a serious academic field, while the waterfront landscape to the north-south direction is a lively campus life. The rich water landscape resources are the important features of the base of Hubei Transportation Polytechnic College. It is planned to form a water surface space from south to north, from narrow to wide, connecting with the Tangxun lake on the west side of the campus. The waterfront environment adopts hydrophilic landscape design. The two sides of the water system are combined with the terrain through the wooden plank road, walking path, white driving ring road and landscape facilities, which provide a space for teachers and students to exchange and experience. As an important area for external display, cherry blossom (or Ginkgo biloba) is also an important viewing area for campus social urbanization.

An artificial mountain is built on the east side of the academic exchange and training center, which mainly includes the square with the local tree, the walking square along the lake, the green square with the evergreen trees, and the sculptures, sketches, fountains, outdoor theater and other activities are also arranged. In the green space of the group, deciduous trees are used to facilitate sun shading in summer and daylighting in winter. Landscape design is carried out by means of garden. Evergreen shrubs are appropriately cut around the buildings, street lamps, seats and public service facilities are arranged around the garden, lawn and road. Garden lights are used in key residential landscape areas to produce a more pleasant effect. Garden lights with pleasant scale are set up in the inner court green space, edge green belt and street green space of the building. Lighting fixtures are set in the green square with a service radius of 15 meters. The selection of lighting fixtures should be consistent with the overall style of the square.

\subsection{Architectural Planning of the New Campus}

The building itself has become a large campus sculpture, which makes the building surpass the building function itself and become an art work. Architectural design is based on the local natural ecological environment, site characteristics, the basic principles of ecology, building technology science and modern scientific and technological means, etc[6]. The design is required to reasonably arrange and organize the relationship between the building and other relevant factors, and at the same time strive for a good sunshine direction, and properly organize natural ventilation, so that the building and the environment could become an organic combination to meet people's living conditions. The comfortable living environment forms a virtuous circle system among people, buildings and natural ecological environment.

Based on the established plane composition, the architectural design uses modern creation techniques shapes a unified and varied architectural form and space by means of connection, interpenetration and other modeling means. The main modeling method of the building shape is the overhanging slope top, which comprehensively uses the changes of horizontal and vertical lines, and emphasizes the shape sense through the material transformation. The building image is elegant, meaningful, and full of vitality. It expresses the unique modern value of the school in a strong and contemporary way, and pays attention to the physical expression of the school building itself. As a landmark 
building, image and text information center has its unique shape, atmosphere and cultural connotation. The student dormitories, public teaching buildings and training buildings are designed in group unit type. In the design, we connect different functions through various corridors, and ground greening. While the duality between curve and straightness, softness and rigidity is the carrier of thinking and aesthetics. It also brings rich and stimulating views that activates the campus atmosphere.

\section{Concluding Remark}

The campus planning under the green concept emphasizes the ecological green campus model. In the campus planning, the original hills and mountains, pond water surface and vegetation and trees should be preserved as much as possible. Taking road greening, square greening and courtyard greening into consideration as a whole, the green ecology surrounding the teaching area is created to form a unique and elegant campus environment.

\section{References}

1. L.Bu, J.N.Sun,A.M.Li,Study on Ecological Planning of water resources utilization in green campus, Engineering construction and design, 04:108111(2014)

2. L.Xia,C.H.Meng, On the planning and design strategy of realizing ecological campus -- Taking Shenyang University of architecture as an example, Architecture and environment, 6: 77-80(2008)

3. T.M.Shi, S.Li, Towards a green campus -- Taking the campus construction of Shenyang University of architecture as an example, Engineering mechanics, s2:9-14(2012)

4. G.H.Tian,W.Liu,Z.K.Miao,X.Ji,Study on the strategy of campus energy conservation based on the green campus standard,Building energy conservation, 01:85-88 + 96(2014)

5. J.J.Yang,L.Y.Shen,J.Y.Zhou,P.F.Zhang,Comparativ e study on Evaluation System of green campus at home and abroad,Building economy, 02:91-94(2016)

6. Q.Yang,Analysis on the application of principles and Countermeasures of green campus planning and design,Journal of Chengdu aviation vocational and technical college, 04:49-51(2013) 